\title{
Salivary glands as a potential gene transfer target for gene therapeutics of some monogenetic endocrine disorders
}

\author{
Antonis Voutetakis ${ }^{1}$, Ioannis Bossis ${ }^{1}$, Marc R Kok ${ }^{1,2}$, \\ Weitian Zhang ${ }^{1}$, Jianghua Wang ${ }^{1}$, Ana P Cotrim ${ }^{1}$, \\ Changyu Zheng ${ }^{1}$, John A Chiorini ${ }^{1}$, Lynnette K Nieman ${ }^{3}$ \\ and Bruce J Baum ${ }^{\mathbf{1}}$ \\ ${ }^{1}$ Gene Therapy and Therapeutics Branch, NIDCR, NIH, DHHS, Bethesda, Maryland 20892, USA \\ ${ }^{2}$ Department of Clinical Immunology and Rheumatology, Academic Medical Center, Amsterdam, The Netherlands \\ ${ }^{3}$ Pediatric and Reproductive Endocrinology Branch, NICHD, NIH, DHHS, Bethesda, Maryland 20892, USA \\ (Requests for offprints should be addressed to B J Baum; Email: bbaum@dir.nidcr.nih.gov)
}

\begin{abstract}
Salivary glands (SGs) exhibit several important features which are also common to endocrine glands: selfcontainment due to a surrounding capsule, highly efficient protein production and the ability to secrete proteins into the bloodstream. We have hypothesized that SGs are potentially useful as gene transfer targets for the correction of inherited monogenetic endocrine disorders. In the present communication, we extend our studies and attempt to test our hypothesis by comparing the efficacy of two commonly used viral vectors and the resulting serum and salivary distribution of transgene encoded hormones.

A low dose $\left(5 \times 10^{9}\right.$ particles $)$ of either an adenoviral serotype 5 (Ad5) vector encoding the human erythropoietin (hEPO) cDNA or an adeno-associated virus serotype 2 (AAV2) vector encoding either the hEPO or human growth hormone (hGH) cDNA was administered to individual submandibular SGs of Balb/c mice. Serum and salivary hEPO and hGH levels were determined at defined time points. Two additional recombinant viruses encoding enhanced green fluorescence protein (GFP)
\end{abstract}

were also used (AdGFP and AAVGFP) in order to perform immunohistochemical analyses of transgenic protein localization in SG sections post-administration.

AAV2 vectors led to stable gene transfer unlike the results with the Ad5 vectors. Indeed, in one mouse we observed hEPO production for a period of two years after administration of AAVhEPO to SGs. hEPO, which is a constitutive pathway secretory protein, was readily secreted into the bloodstream from the SGs, yielding therapeutically adequate serum levels. Conversely, hGH, a regulated secretory pathway protein, was preferentially secreted into saliva.

SGs may be an attractive candidate target tissue for gene therapeutics of some monogenetic endocrine deficiency disorders. At present, AAV2 vectors seem particularly useful for such applications, and transgenes encoding constitutive secretory pathway hormones are more suitable for this application with SGs than those encoding regulated secretory pathway hormones.

Journal of Endocrinology (2005) 185, 363-372

\section{Introduction}

Inherited monogenetic endocrine disorders are attractive candidates for gene therapy. The optimal gene therapy target is the physiological production site of the deficient hormone (e.g. pituitary gland somatotropes for growth hormone) to allow for regulated hormone secretion (Dannies 2002). However, the delicate nature and lifesustaining role of these highly differentiated organs along with current biotechnology limitations render such approaches unappealing, especially with respect to non-life threatening hormone deficiencies. Various tissues such as muscle, liver or lung have thus far been primarily targeted to overcome this obstacle (Barzon et al. 2000, Auricchio et al. 2002, Goldspink 2003, Harding et al. 2004).

We have considered the salivary glands (SGs) to be an unusual, yet promising target tissue for gene therapeutics (i.e. use of the gene as a drug: Crystal 1995, Voutetakis et al. 2004a,b, Zufferey \& Aebischer 2004). The classic physiological role of SGs is to produce an exocrine secretion, saliva. In addition to water and electrolytes, saliva contains digestive enzymes, anti-microbial proteins, calcium binding phosphoproteins, growth factors and mucoproteins suggesting that SGs exhibit very efficient protein production mechanisms (Amerongen \& Veerman 2002). These salivary exocrine proteins are stored in 
granules and exit into saliva following a predominant regulated pathway (Castle \& Castle 1998). SGs also exhibit a constitutive secretory pathway leading towards the interstitium and bloodstream (Castle \& Castle 1998). Convincing evidence has confirmed the endocrine secretion of digestive enzymes by SGs in the serum through this constitutive pathway and proved their presence in the bloodstream to be neither inadvertent nor due to pathology (Isenman et al. 1999). Importantly, both secretory pathways (constitutive and regulated) operative in SGs have proven readily available for conveying expressed transgenic secretory proteins (Baum et al. 1999, 2002).

SGs thus exhibit several important features of the various endocrine glands: highly efficient protein production and ability to secrete proteins into the bloodstream, as well as self-containment due to the surrounding capsule. Consequently, we have hypothesized that SGs may be an attractive candidate for gene therapeutics for monogenetic endocrine deficiency disorders (i.e. to act as a surrogate endocrine gland: Voutetakis et al. 2004b). In the present report, we have extended our studies and directly compared the efficacy of two commonly used viral vectors to mediate gene transfer to SGs, as well as the resulting serum and salivary distribution of two transgene-encoded hormones, human growth hormone (hGH) and human erythropoietin (hEPO). These hormones exit through different secretory pathways (the regulated and constitutive respectively) when synthesized in their primary production sites (anterior pituitary gland and kidney respectively) and therefore are useful as model proteins for 'proof of concept' experiments (Mujais et al. 1999, Dannies 2002).

We constructed an adenoviral serotype 5 (Ad5) vector encoding the hEPO cDNA and two adeno-associated virus serotype 2 (AAV2) vectors encoding the hGH and hEPO cDNA respectively. A low dose $\left(5 \times 10^{9}\right.$ particles/ animal) of each recombinant virus was administered to individual submandibular SGs of Balb/c mice via cannulation of the main excretory ducts (Baum et al. 2002). Serum and salivary concentrations of both hGH and hEPO were measured at distinct time-points post administration. Target cell localization was assessed by immunohistochemistry after transfer of the cDNA for green fluorescence protein (GFP) using either an Ad5 or an AAV2 vector.

\section{Materials and Methods}

Construction of AdhEPO, AdGFP, AAVhEPO, $A A V h G H$ and $A A V G F P$

Generation of the E1 ${ }^{-}$, replication deficient Ad5 vectors was performed as previously described (He et al. 1998). Briefly, 293 cells were co-transfected with the shuttle plasmid pAC-CMV-pLpA containing either the hEPO cDNA or the GFP cDNA, and the adenoviral plasmid
pJM17 using a calcium phosphate transfection system (Life Technologies, Gaithersburg, MD, USA) to generate the recombinant vectors AdhEPO and AdGFP. The cytomegalovirus (CMV) promoter was employed to drive both hEPO and GFP expression. Dr Y Terada (Tokyo Medical and Dental University, Tokyo, Japan) generously provided the hEPO cDNA. Recombinant viruses were plaque screened, propagated in 293 cells, and purified by $\mathrm{CsCl}$ gradient centrifugation, as described (He et al. 1998, Baum et al. 1999). After purification, recombinant viruses were dialyzed against 4 liters dialysis buffer containing 10\% glycerol, $0 \cdot 1 \mathrm{M}$ Tris (pH 7.4), $5 \mathrm{mM} \mathrm{MgCl} 2$, for $4 \mathrm{~h}$ at $4{ }^{\circ} \mathrm{C}$ and stored in aliquots at $-80{ }^{\circ} \mathrm{C}$ for later use. Vector titers were initially determined by measuring the optical density at $260 \mathrm{~nm}$ as described (Mittereder et al. 1996), and then by real-time quantitative PCR (QPCR) using transgene-specific primers. Vector concentrations used herein were calculated based on the QPCR assay using the ABI Prism 7700 Sequence Detector (Applied Biosystems, Foster City, CA, USA).

Generation of the replication deficient AAV2 vectors was performed as previously described (Chiorini et al. 1995, Kaludov et al. 2002, Voutetakis et al. 2004b). Briefly, $293 \mathrm{~T}$ cells were co-transfected by calcium phosphate precipitation with the trans plasmids pMMTV2.1 (provides the AAV serotype 2 Rep and Cap genes), pAd12 (provides adenoviral helper genes) and one of the cis plasmids pAAVhEPO, pAAVhGH or pAAVGFP, containing the hEPO, the hGH or GFP cDNA respectively, flanked by the AAV2 ITRs to generate the recombinant viral vectors AAVhEPO, AAVhGH, or AAVGFP respectively. The Rous sarcoma virus (RSV) promoter was employed to drive transgene expression in these AAV2 vectors. The cells were harvested $48 \mathrm{~h}$ post-transfection and a crude viral lysate was obtained after three freezethaw cycles. The lysate was treated with benzonase, adjusted to a refractive index of 1.372 by addition of $\mathrm{CsCl}$ and centrifuged at 38000 r.p.m. (SW-41 rotor) for $65 \mathrm{~h}$ at $20{ }^{\circ} \mathrm{C}$. Equilibrium density gradients were fractionated and fractions with a refractive index of 1.369-1.375 were collected and stored at $4{ }^{\circ} \mathrm{C}$ and assayed for infectious activity. Immediately before experiments, viral fractions were dialyzed against $0.9 \% \mathrm{NaCl}$. The number of AAV genomes (particles) was estimated using a QPCR assay, amplifying an RSV sequence using the ABI Prism 7700 Sequence Detector (Applied Biosystems). Vector titers and concentrations presented are based on the QPCR assay.

\section{Mice, gene transfer and salivary and serum collections}

Animal studies were approved by the NIDCR Animal Care and Use Committee and the NIH Biosafety Committee. All procedures were conducted in accordance with the International Association for the Study of Pain standards. Male Balb/c mice were obtained from the Division of Cancer Treatment, NCI, Bethesda, MD, 
USA. Three groups of mice $\left(n=5\right.$ each) received $5 \times 10^{9}$ particles/animal (suspended in $50 \mu \mathrm{l}$ of $0.9 \% \mathrm{NaCl}$ ) of AdhEPO, AAVhEPO or AAVhGH respectively by retrograde ductal delivery to their submandibular salivary glands (Baum et al. 2002, Yamano et al. 2002). One additional group of $\mathrm{Balb} / \mathrm{c}$ mice $(n=5)$ was given $50 \mu \mathrm{l}$ $0.9 \% \mathrm{NaCl}$, thus serving as the control group. Mild anesthesia was induced with $1 \mu \mathrm{l} / \mathrm{g}$ body weight of a $60 \mathrm{mg} / \mathrm{ml}$ ketamine (Phoenix Scientific, St Joseph, MO, USA) and $8 \mathrm{mg} / \mathrm{ml}$ xylazine (Phoenix Scientific) solution given intramuscularly (i.m.). Mice given AdhEPO also received an i.m. injection of $100 \mu \mathrm{g}$ dexamethasone at the time of viral delivery and $24 \mathrm{~h}$ later to diminish virusmediated acute inflammation (Baum et al. 2002). Blood samples were obtained by retro-orbital plexus bleeding at distinct time-points: (i) prior to, and at weeks 1, 2, 3 and 4 after administration of the AdhEPO vector and (ii) prior to, and at weeks 2, 4, 8, 12 and 16 after administration of AAVhGH, AAVhEPO and $0.9 \% \mathrm{NaCl}$. For one mouse, originally reported in Voutetakis et al. (2004b), blood samples were obtained up to 2 years after AAVhEPO administration (see Fig. 5). Whole saliva was also collected at week 4 of the experiment from the AAVhGH, AAVhEPO and control groups as described (Yamano et al. 2002), after stimulation of secretion using $0.5 \mathrm{mg}$ pilocarpine $/ \mathrm{kg}$ body weight administered subcutaneously. Hematocrits (Hcts) were determined using microhematocrit capillary tubes (Fisher Scientific, Pittsburgh, PA, USA) throughout the experiment.

In addition, four mice were given $10^{10}$ particles of either AdGFP or AAVGFP $(n=2$ per group; one gland each). The AdGFP-treated animals were killed at day 2 or week 6 of the experiment. The AAVGFP-treated animals were killed at week 6 . Both SGs (i.e. transduced and not transduced) from all 4 animals were removed at the time of death, fixed in formalin and embedded in paraffin for histological analyses. Sections were cut at $5 \mu \mathrm{m}$ thickness. Transduced cells were detected by immunohistochemistry (GFP positive staining) using the streptavidin-biotin peroxidase complex method. Briefly, sections were deparaffinized, endogenous peroxidase was blocked, and sections were incubated for $1 \mathrm{~h}$ with a polyclonal primary antibody against GFP (1/200 dilution; ab290; Abcam, Cambridge, MA, USA) raised in rabbits. Staining was developed by using a biotinylated goat antibody (Vector Laboratories) directed against the primary antibody, followed by 3, 3'-diaminobenzidine (SK-4100; Vector Laboratories, Burlingame, CA, USA). Sections were lightly counterstained with hematoxylin. Sections from the opposite, non-transduced SGs from the same mice served as controls.

\section{Quantification of $h G H$ and $h E P O$}

Serum was obtained by centrifugation of the blood samples at $5000 \times \boldsymbol{g}$ for $2 \mathrm{~min}$ at room temperature. Levels of hGH in mouse serum and saliva were detected with a chemiluminescence immunoassay kit (Nichols Institute Diagnostics, San Juan Capistrano, CA, USA) according to the manufacturer's instructions. The lower limit of detection was $20 \mathrm{pg} / \mathrm{ml}$. Levels of hEPO in mouse serum and saliva were determined by an ELISA using commercial assay kits (R\&D Systems, Minneapolis, MN, USA). The lower limit of detection was $0.6 \mathrm{mU} / \mathrm{ml}$. Assays were performed according to the manufacturer's instructions.

\section{Anti-hGH antibody detection}

The presence of anti-hGH antibodies in mouse sera was evaluated indirectly. For this, $98 \mu \mathrm{l}$ of an hGH-containing solution $(2 \mathrm{ng} / \mathrm{ml})$ and $2 \mu \mathrm{l}$ mouse serum obtained 12 weeks post AAVhGH administration were mixed. The mouse serum was either undiluted or diluted using the hGH assay dilution buffer in a 1:1 to $1: 512$ ratio. As a result, the final mouse serum dilutions in the hGH solution ranged from 1:50 to 1:25 600. The (hGH+mouse serum) samples were incubated at $37^{\circ} \mathrm{C}$ for $30 \mathrm{~min}$. Two control samples containing $98 \mu \mathrm{l}$ of the same hGH solution $(2 \mathrm{ng} / \mathrm{ml})$ and $2 \mu \mathrm{l}$ mouse serum obtained either from a control animal or an AAVhEPO-treated animal were also included. The above-described chemiluminescence immunoassay hGH kit was used to measure all the samples. Mouse anti-hGH antibodies contained in the mouse serum bind to $\mathrm{hGH}$, resulting in interference of detection (i.e. inhibit detection).

\section{Data analysis}

Data are reported as mean values \pm S.E. Statistical analyses employed repeated measures ANOVA for the long term comparison of the AdhEPO- and AAVhEPO-treated groups, with Fisher's protected least significant difference (PLSD) for within time point comparison. A paired $t$-test was used for the comparison of the saliva and serum distribution within the AAVhEPO- and AAVhGHtreated groups (Statview Version 5.0.1; SAS Institute, Cary, NC, USA).

\section{Results}

For all animals used in our experiments, mean serum hEPO and hGH levels were non-detectable and mean Hct levels ( \pm S.E.) were $59 \cdot 6 \pm 2.5 \%$ prior to vector administration (week 0). Mean serum hEPO levels from the AdhEPO- and AAVhEPO-treated groups are depicted in Fig. 1 (16 week period).

In the AdhEPO-treated group $\left(5 \times 10^{9}\right.$ particles/ animal; $n=5$ ), serum hEPO levels were increased one week post administration (mean \pm S.E.: $94 \pm 27 \mathrm{mU} / \mathrm{ml}$; $n=4$, one animal died). Hct levels at week 1 were also increased $(72 \cdot 2 \pm 1 \%)$. At week 2 and thereafter, serum hEPO levels were undetectable. Hct levels at week 2 fell 


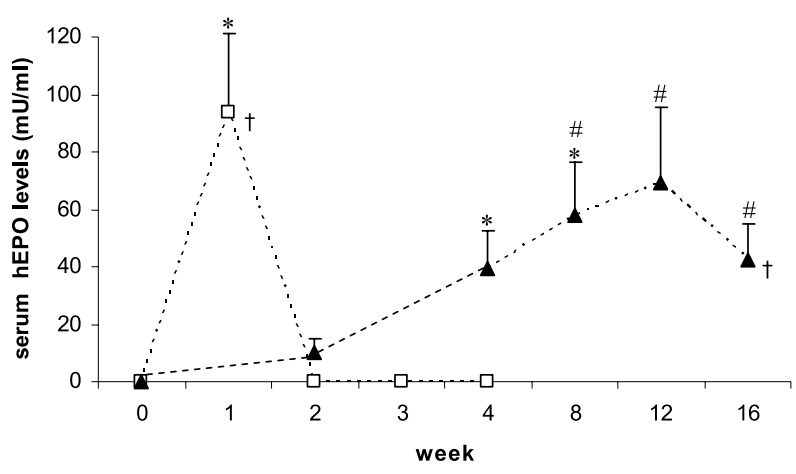

Figure 1 Serum hEPO levels at various time points after vector delivery to mouse submandibular glands. Data are the mean $\left(+\right.$ S.E.) values after $5 \times 10^{9}$ particles were administered to animals ( $n=5$; each group). In the AdhEPO-treated group ( $\square$ ), hEPO levels were significantly increased one week post administration $\left({ }^{*} P<0 \cdot 01\right)$. The mean $\mathrm{Hct}$ level at week 1 was $72 \%$. At week 2 and thereafter, hEPO levels became undetectable and Hct levels at week 4 were back to pre-administration levels (61\%). In the AAVhEPO-treated group ( $\boldsymbol{\Delta}$ ), hEPO levels remained elevated throughout the experiment ( 16 weeks; F: $11 \cdot 5, P<0 \cdot 01$ ). The hEPO values were significantly increased at week 4 and 8 when compared with the previous available measurement respectively $\left({ }^{\star} P<0 \cdot 05\right)$. Transgene expression was relatively stable thereafter since hEPO levels at 8,12 and 16 weeks were not different from one another (\#P>0.05). Hct levels increased in parallel with serum hEPO levels (see text; mean Hct value at week 16 was $86 \%$ ). Comparison between serum and salivary hEPO secretion at week 4 is depicted in Fig. 2. Both serum and salivary hEPO levels were undetectable in the AAVhGH and control (naïve) groups $(n=5$ each; controls receiving $0.9 \% \mathrm{NaCl}$ ), in which Hct levels remained $\sim 60 \%$ until the end of the experiment. $t$, one animal died prior to this timepoint.

towards baseline $(68 \pm 1 \cdot 2 \%)$ and at week 4 were back to pre-administration levels $(61 \pm 2 \%)$. The elevation of serum hEPO levels at week 1 was significant (F: 11.7, $P<0 \cdot 01)$.

In the AAVhEPO-treated group $\left(5 \times 10^{9}\right.$ particles/ animal; $n=5$ ), serum hEPO levels gradually increased to the 12 week measurement $(69 \cdot 4 \pm 26 \cdot 4 \mathrm{mU} / \mathrm{ml})$. The overall elevation of serum hEPO levels was significant (F: $11 \cdot 5, P<0 \cdot 001)$. The hEPO levels significantly increased between weeks 0,4 and $8(P<0 \cdot 05)$. There was no statistical difference in the serum hEPO levels when comparing results between weeks 8,12 and 16. The mouse with the highest serum hEPO levels at week 12 $(168 \mathrm{mU} / \mathrm{ml})$ died at week 14 . Consequently, although serum hEPO levels remained relatively stable at week 16 (the longest time studied) with respect to each of the remaining mice $(n=4)$, the mean serum hEPO levels appear slightly decreased albeit not significantly $(42.5 \pm$ $12 \cdot 2 \mathrm{mU} / \mathrm{ml})$. Hct levels increased significantly $(P<0 \cdot 01$ when compared with both pre-administration levels of the AAVhEPO-treated group and the control group (naïve mice) at the same time point) and occurred in parallel with serum hEPO levels $(77 \cdot 2 \pm 4 \cdot 2 \%, 82 \cdot 6 \pm 3 \cdot 9 \%$ and $86 \cdot 2 \pm 2 \%$ at weeks 4,8 and 16 respectively). Mean
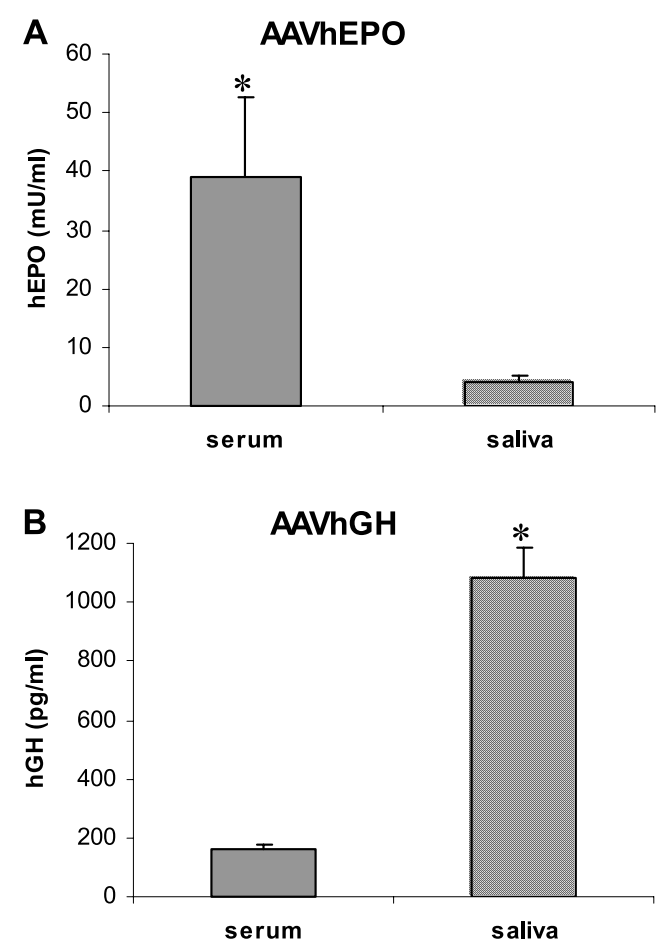

Figure 2 Transgene encoded hEPO and hGH continue to follow the same secretory pathway (constitutive and regulated respectively) as in their primary site of production. (A) Mean serum and salivary hEPO levels (+ S.E.) at week 4 after AAVhEPO administration in mouse submandibular glands (long-term data are depicted in Fig. 1). hEPO produced in SGs is predominantly secreted into the bloodstream (constitutive pathway); salivary levels are $\sim 10 \%$ of the serum levels $\left({ }^{*} P<0.05\right.$ with paired $t$-test). Both serum and salivary hEPO levels were undetectable in the AAVhGH group. (B) Mean serum and salivary hGH levels (+ S.E.) at week 4 after AAVhGH administration in mouse SGs. hGH produced in SGs is predominantly secreted into saliva (regulated pathway); serum levels are $\sim 15 \%$ of salivary levels ( ${ }^{\star} P<0.05$ with paired $t$-test). Both serum and salivary hGH levels were undetectable in the AAVhEPO group. Data shown for hEPO and hGH levels are based on experiments with 5 and 4 mice respectively.

salivary hEPO levels at week 4 (Fig. 2A) were $3 \cdot 8 \pm$ $1.1 \mathrm{mU} / \mathrm{ml}$, markedly less $(P<0 \cdot 05)$ than mean serum hEPO levels at the same time point $(39 \cdot 2 \pm 13.6 \mathrm{mU} / \mathrm{ml})$. Both serum and salivary hEPO levels were undetectable in the AAVhGH and control groups $(n=5$ each; controls receiving $0.9 \% \mathrm{NaCl}$ ), in which $\mathrm{Hct}$ levels remained $\sim 60 \%$ until the end of the experiment.

In the AAVhGH-treated group $\left(5 \times 10^{9}\right.$ particles/ animal; $n=5$ ) mean salivary hGH levels were significantly increased at week 4 post administration (Fig. 2B; $1084 \pm$ $102 \mathrm{pg} / \mathrm{ml})$. Although mean serum hGH levels also increased $(151.5 \pm 17 \cdot 3 \mathrm{pg} / \mathrm{ml})$, the difference between salivary and serum distribution of hGH was significant $(P<0 \cdot 05)$. By week 8 and thereafter, however, both serum and salivary hGH levels were undetectable (not shown). A 
mouse anti-hGH antibodies inhibit hGH detection

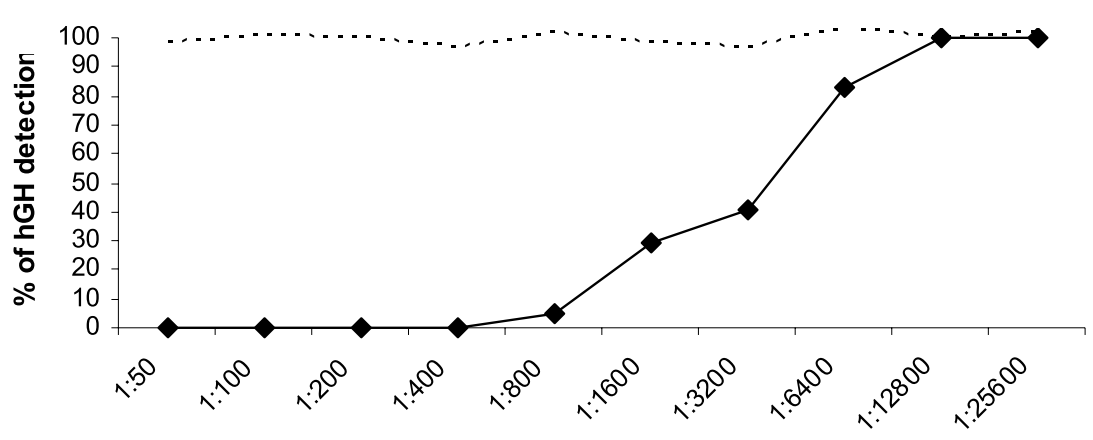

mouse serum dilution

Figure 3 Inhibition of hGH detection due to the presence of anti-hGH antibodies in mouse serum 12 weeks after AAVhGH administration. Serial dilutions (1:50-1:25 600) of mouse serum (serum from AAVhGH-treated, as well as from naïve and AAVhEPO-treated mice as controls) were mixed together with an hGH-containing solution $(2 \mathrm{ng} / \mathrm{ml})$. A chemiluminescence immunoassay kit was used to measure hGH levels after incubation at $37^{\circ} \mathrm{C}$ for $30 \mathrm{~min}$. Marked inhibition of detection of hGH was observed with respect to the hGH control (no mouse serum used; considered as $100 \%$ of detection) when serum from AAVhGH-treated animals was used $(\bullet)$. The $50 \%$ inhibiting concentration of the mouse serum was between 1:3200 and 1:6400. No inhibition of hGH detection was observed when the same hGH solution was incubated with serial dilutions of serum from either naïve animals (given $0.9 \% \mathrm{NaCl}$; data not shown) or AAVhEPO-treated animals (dotted line). All assays were performed in duplicate (mean values are shown).

high amount of mouse anti-hGH antibodies was found in serum obtained from the AAVhGH-treated group at week 12 after administration. The $50 \%$ inhibiting concentration of the mouse serum was between 1:3200 and 1:6400 (Fig. 3). No inhibition of hGH detection was observed when serum from both control (naïve) animals or AAVhEPOtreated animals was used. Both serum and salivary hGH levels were undetectable in the AAVhEPO and naive mouse control groups $(n=5$; controls receiving $0.9 \%$ $\mathrm{NaCl}$.

In the AdGFP-treated animals GFP was only detected in sections obtained two days after viral delivery. Both acinar and ductal cells were positively stained (Fig. 4). Infiltration of inflammatory cells and a disruption of the normal morphology of SGs was also observed (Fig. 4B). No GFP-positive staining was observed at week 6 after AdGFP administration (data not shown). In contrast, in the AAVGFP-treated animals GFP was detected at week 6 after administration. Only ductal cells were positively stained and no infiltration of inflammatory cells was observed (Fig. 4C). No staining was detected in the control sections obtained from the opposite (i.e. not cannulated) SG from each mouse (Fig. 4D).

\section{Discussion}

Recent advances in gene transfer to replace therapeutic proteins, although significant are far from defining a universal vector or delivery site. At present, vectors and gene therapy approaches are best evaluated in a diseaseand/or system-specific manner. Our efforts have focused on the study of a potentially useful target site for some endocrine disorders, the SGs.

Human SGs are not-critical-for-life organs with considerable secretory abilities, able to produce $0.75-1.5$ liters of saliva daily, and to secrete protein into both the gastrointestinal tract and the bloodstream (Isenman et al. 1999). These unique features motivated us to suggest SGs as potential targets for gene therapeutics. Efficient production and secretion of transgene-encoded proteins can occur with vector doses 10 to 100 times lower than required at many commonly used tissue target sites (e.g. muscle, liver, lung: Snyder et al. 1997, Almazan et al. 2000, Bohl et al. 2000, Chao et al. 2001, Auricchio et al. 2002, Samakoglu et al. 2002, Johnston et al. 2003, Voutetakis et al. 2004a,b, Zufferey \& Aebischer 2004). The use of lower vector doses likely reduces the potential danger of a viral vectorrelated adverse event.

Moreover, the SGs are well encapsulated (i.e. selfconfined) organs (Baum et al. 2002). Under our experimental conditions, we have previously shown that dissemination of the vector beyond the SGs, and subsequent stable infection of other tissues post-administration with such low viral doses, is below the QPCR assay sensitivity levels (Kok et al. 2003, Voutetakis et al. 2004b). To further ensure safety in clinical studies, use of SG tissue-specific promoters will likely be beneficial (Zheng et al. 2001). 
Importantly, the number of viral copies present in the SGs and the transgene-encoded protein levels synthesized are strongly correlated, facilitating a crude yet useful control over protein production (Voutetakis et al. 2004b). Tighter regulation of transgene expression in SGs can be achieved

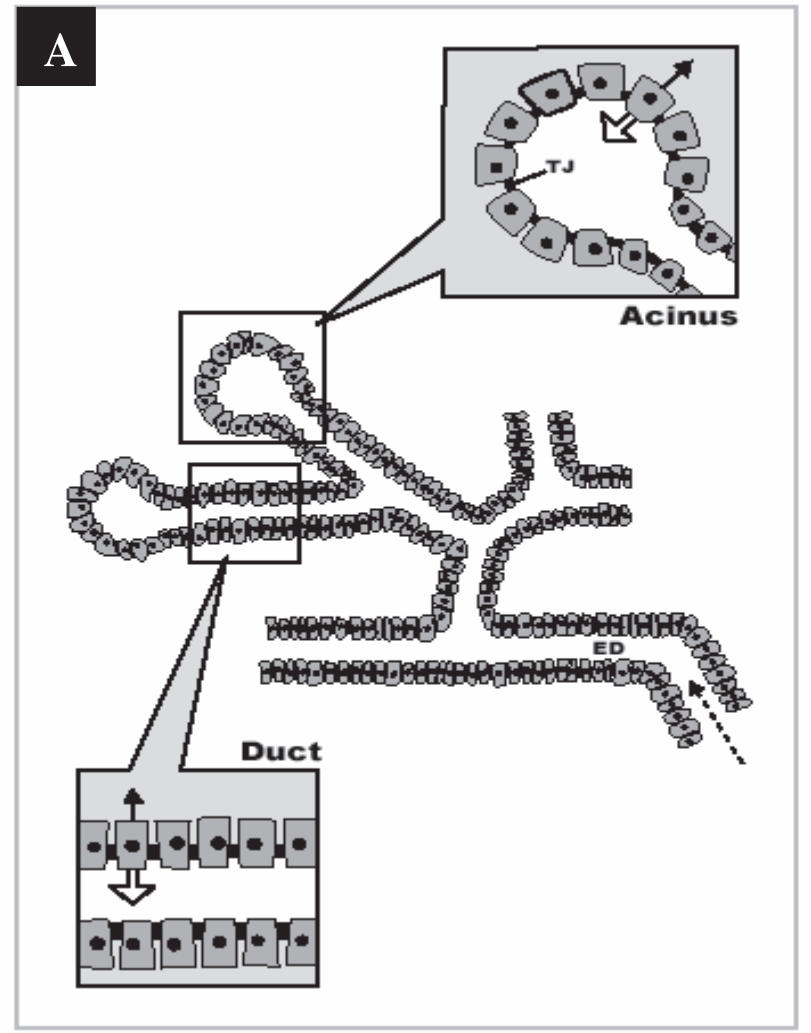

through small molecule drug-mediated activation of transcription (Wang et al. 2004).

Gene transfer to SGs can be accomplished in a relatively non-invasive manner by intra-oral cannulation of the main excretory ducts. Vector is infused in a retrograde
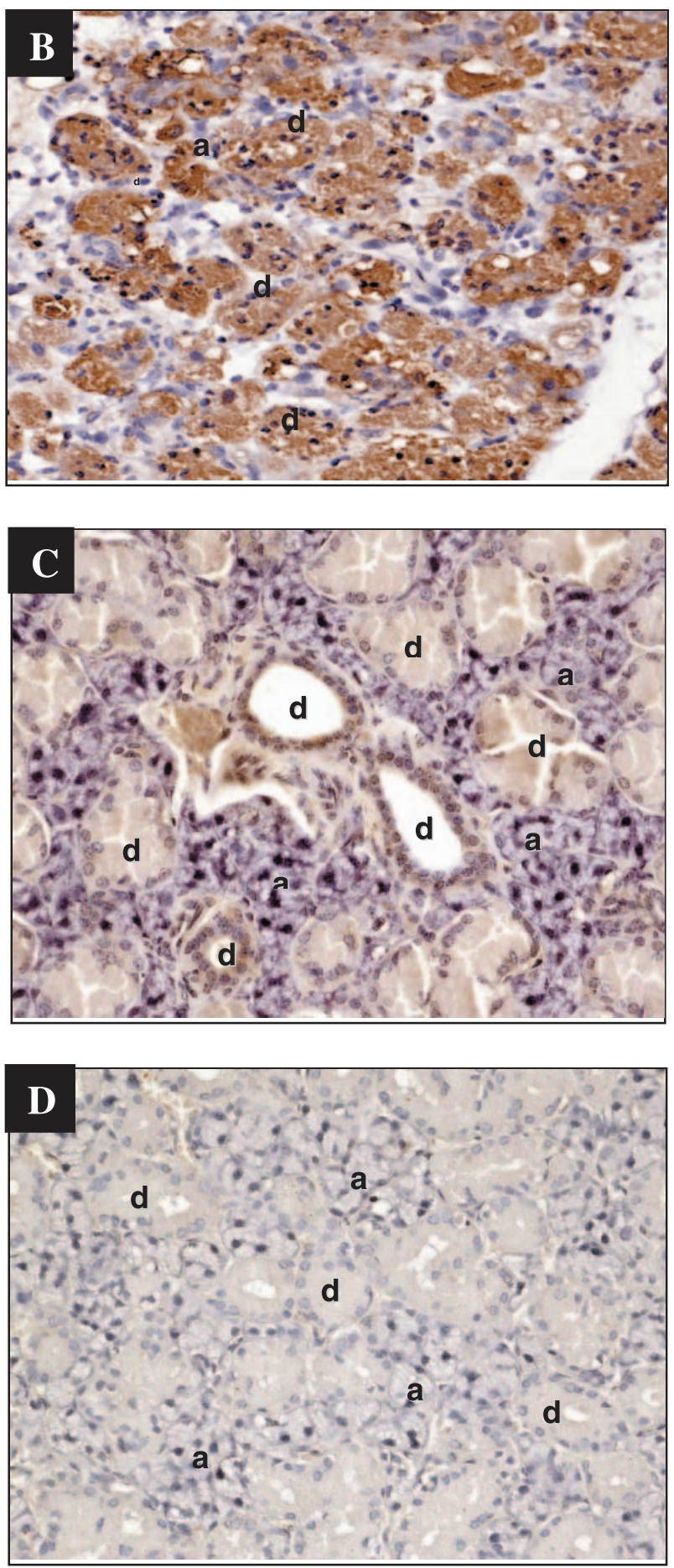
direction through the cannula, after suspension in a diluent buffer (Fig. 4A; Baum et al. 2002). The procedure is similar to the one performed clinically without anesthesia for contrast radiographs of the SGs. SGs consist of two general types of well differentiated and slowly dividing epithelial cells, acinar (in humans $>80 \%$ of the parenchymal cells) and ductal (Cook et al. 1994). Ductal cells form an extensive tubular network conducting saliva to the mouth, while acinar cells are found at the distal end of the ductal system (Fig. 4A). Most SG epithelial cells exist as a monolayer, lining up along the luminal system and therefore are a potential target after vector administration (Fig. 4A).

SG cells exhibit at least two distinct secretory pathways: a predominant regulated one leading to exocrine protein secretion into saliva via zymogen granules, and a constitutive one mainly leading to endocrine secretion into the bloodstream (Fig. 4A; Castle \& Castle 1998, Baum et al. 1999, Isenman et al. 1999). Secretory proteins produced as transgene products in SGs, after viral-mediated gene transfer, continue to follow the same general secretory pathway as in their primary site of production (Baum et al. 1999). Physiologically, hGH is synthesized in somatotropes residing in the anterior pituitary gland and is secreted via the regulated pathway, and hEPO is synthesized in kidney tubular epithelial cells and is secreted via the constitutive pathway (Mujais et al. 1999, Dannies 2002). The pathway followed for secretion is not affected by general protein structure, since EPO and GH proteins are of a similar size and tertiary structure (Bazan 1989).

Ad5 and AAV2 vectors are able to infect both nondividing and slowly dividing cells (Lai et al. 2002). Consequently, these vectors can be used for transferring genes to SGs in vivo (Baum et al. 2002). Data herein presented constitute the first direct comparison between AAV2 and Ad5 vectors in salivary glands in any species. In the AdhEPO-treated group, mean serum hEPO levels were significantly elevated one week after administration, but became undetectable thereafter (Fig. 1).
Ad5 vectors elicit a potent host cellular and humoral immune response in SGs as in other tissues (Fig. 4B; Adesanya et al. 1996, Kagami et al. 1998). As a consequence, vector DNA and transduced epithelial cells are rapidly destroyed and transgene-encoded protein production ceases. Thus, first-generation Ad5 vectors do not seem suitable for gene transfer to SGs with respect to management of monogenetic endocrine deficiencies, as such applications require long-term expression of the transgene.

AAV2 is a relatively small $(<5 \mathrm{~kb})$, naturally replicationincompetent member of the parvovirus family. There is no evidence that AAV2 is an etiological agent for human disease (Kay et al. 2001). Since AAV2 is a small vector, there is relatively limited space available for the transgene cassette (i.e. requiring at least the promoter, transgene, and polyadenylation sequence). Importantly, in vivo recombinant AAV2 vectors can mediate long-term transgene expression in salivary glands and other tissues (Yamano et al. 2002, Voutetakis et al. 2004b).

After AAVhGH administration to the SGs, hGH was predominantly secreted into saliva through the selective and multistep regulated secretory pathway. Entry into the regulated pathway can be saturated by the overexpression of the transgene product (Marmorstein et al. 2000, Hoque et al. 2001). The 'overflow' can then exit salivary epithelial cells through the constitutive pathway and be secreted into the bloodstream inefficiently (He et al. 1998, Hoque et al. 2001). Accordingly, serum concentrations of hGH shown herein were relatively low compared with those in saliva (Fig. 2B). We were unable to follow hGH production after week 4 of the experiment probably due to a substantial anti-hGH humoral response (Fig. 3). However, our results from the week 4 time-point clearly show that although possible, it is inefficient to deliver a regulated secretory pathway (RSP) transgenic hormone into the bloodstream from mammalian SGs. Most of the produced peptide will be physiologically wasted by being secreted via saliva into the gastrointestinal tract.

\footnotetext{
Figure 4 (A) Schematic representation of the structure of murine salivary glands in situ. Most SG epithelial cells exist as a monolayer, lining up along the luminal system. SGs principally consist of two general types of epithelial cells, acinar and ductal. SG cells exhibit a predominant regulated secretory pathway leading to saliva (through dense core secretory granules across the apical membrane; white arrow) and a constitutive pathway leading into the interstitium and the bloodstream (across the basolateral membrane; black arrow). Ductal cells form an extensive tubular lumen conducting saliva, via the excretory duct (ED), to the mouth. Acinar cells are found at the distal end of the ductal system, and form the acini. Tight junctions (TJ) between SG cells are also depicted (black connections). Gene transfer to SGs can be accomplished in a relatively non-invasive manner by intra-oral cannulation of the main excretory ducts. After vector infusion in a retrograde direction (dotted arrow) through the cannula, almost the entire SG cell population is a potential target. (B, C, D) Immunohistochemical detection of green fluorescence protein (GFP) expression in mouse submandibular glands after administration of $10^{10}$ particles of either adenoviral (AdGFP) or adeno-associated viral (AAVGFP) vectors. Sections were prepared at various time points after vector delivery, and GFP expression detected using an anti-GFP antibody. Sections were counterstained with hematoxylin. Representative examples of acini (a) and ducts (d) are depicted. (B) Two days after administration, AdGFP led to GFP production in both acinar and ductal cells (brown color). Infiltration of inflammatory cells and disruption of the SGs normal morphology was also observed. No GFP producing cells were observed at week 6 after AdGFP delivery, probably due to rapid immune-mediated destruction of infected cells (Adesanya et al. 1996, Kagami et al. 1998). SGs at week 6 appeared to have a normal morphology with no inflammatory infiltrates present (data not shown). (C) At week 6 after administration, AAVGFP-mediated transgene expression (brown color) is clearly evident. Only ductal cells are infected and no infiltration of immune cells is observed. (D) No GFP immunostaining was detected in the control tissue sections obtained from the contralateral SG.
} 
There are a number of reports suggesting that RSP sorting is signal dependent (i.e. amino acid sequence dependent; e.g. Kelly 1985, Gerdes \& Glombik 1999, Loh et al. 2002). The example of pro-insulin mis-sorting both in humans and in transgenic mice due to point mutations in the insulin gene is well described (Chan et al. 1987, Carroll et al. 1988). Consequently, one strategy to enhance hGH (and other regulated pathway proteins) secretion into the constitutive pathway and therefore into the bloodstream could involve manipulation of putative sorting signals (Wang et al. 2005). An alternative strategy is to induce mis-sorting of RSP transgenic hormones by using intracellular alkalinizing drugs, such as hydroxychloroquine (Hoque et al. 2001).

After AAVhEPO administration to the SGs, hEPO was secreted preferentially into the bloodstream following the constitutive pathway. Salivary concentrations of hEPO were $\sim 10 \%$ serum levels (Fig. 2 A). SGs were able to sustain serum hEPO levels well above the normal range (10-30 mU/ml; Kendall 2001) throughout the 16 weeks of the current experiment, and longer, as we have reported (Voutetakis et al. 2004b). Erythropoietin targets erythroid progenitor cells in the bone marrow and increases red blood cell production and therefore Hct levels (Kendall 2001). Circulating hEPO proved to be not only therapeutically adequate but also functional in the present and in earlier studies: Hct levels in both AdhEPO- and AAVhEPO-treated groups generally followed serum hEPO levels (see Results). This indicates that SGs are capable of the necessary post-transcriptional modifications required for the secretion and biological activity of this transgene product (Dube et al. 1988).

In previously published experiments we have shown AAV2-mediated transgene expression for up to 54 weeks in mice (Voutetakis et al. 2004b). Interestingly, a mouse included in that original study (receiving $5 \times 10^{9}$ particles of AAVhEPO), has survived for more than two years after vector administration, and despite the sustained elevated Hct levels $(\sim 70 \%)$. Serum hEPO levels in this mouse were quite stable throughout this two-year period (Fig. 5). No inflammatory infiltrates or structural abnormalities have been observed in gland sections after AAV2 vector administration, suggesting that retrograde ductal delivery per se and AAV2 transduction do not cause any irreversible damage to the SG tissue (Fig. 4C; Yamano et al. 2002, Voutetakis et al. 2004b).

Our data suggest that SGs could be an alternative gene delivery target for some monogenetic endocrine disorders, potentially offering a safer way of vector administration without limiting the efficiency of hormone production. Using the SGs for such applications is consistent with the primary role of these cells, i.e. it takes advantage of already existing normal physiological functions. AAV2 vectors currently appear as the gene transfer vector of choice for such applications, since they appear safe and mediate stable, uneventful and long-term transgene expression.

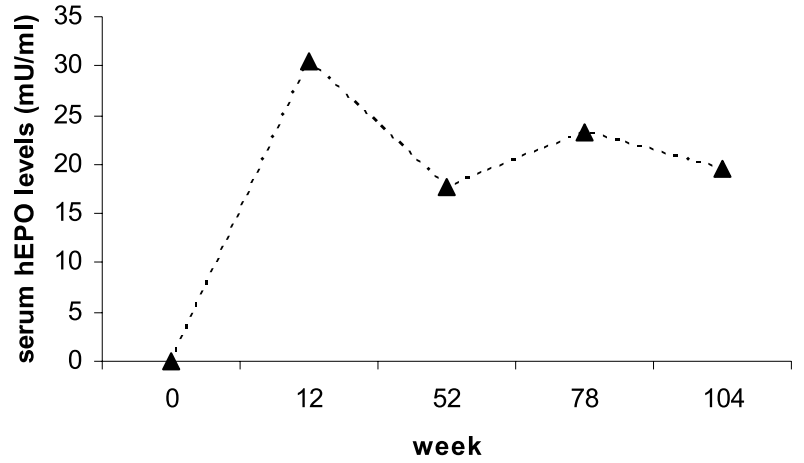

Figure 5 Serum hEPO levels at various time points after retrograde ductal delivery to a single mouse $\left(5 \times 10^{9} \mathrm{AAVhEPO}\right.$ viral particles to one submandibular gland). This mouse has survived from an original group $(n=5)$ transduced with AAVhEPO and reported in Voutitakis et al. (2004b). This mouse was able to produce relatively stable serum hEPO levels for two years after vector administration. The Hct level at week 104 was $70 \%$.

With respect to transgene products, constitutive pathway secretory proteins currently appear to be more suitable for SG applications, since RSP proteins are preferentially secreted into saliva. Efficient strategies for re-direction of the latter must be achieved before useful clinical applications with RSP proteins can be realized.

\section{Acknowledgements}

We thank Dr Martin Kriete and Mr Miltiades Papa for their invaluable help with animal studies, Mr Richard Hayward and Ms Kathleen Bolland (NIDCR, Sequencing Core Facility) for sequencing the vectors used in the experiments presented herein, Dr Gabor Illei for assistance in statistical analyses, and Ms Brenda Spuij for help with the schematic diagrams.

\section{Funding}

M R K was supported by the Dutch Arthritis Foundation NR 02-01-302. The authors declare that there is no conflict of interest that would prejudice the impartiality of this scientific work.

\section{References}

Adesanya MR, Redman RS, Baum BJ \& O’Connell BC 1996 Immediate inflammatory responses to adenovirus-mediated gene transfer in rat salivary glands. Human Gene Therapy 7 1085-1093.

Almazan F, Gonzalez JM, Penzes Z, Izeta A, Calvo E, Plana-Duran J \& Enjuanes L 2000 Engineering the largest RNA virus genome as an infectious bacterial artificial chromosome. PNAS 97 5516-5521.

Amerongen AV \& Veerman EC 2002 Saliva - the defender of the oral cavity. Oral Diseases 8 12-22. 
Auricchio A, O'Connor E, Weiner D, Gao GP, Hildinger M, Wang L, Calcedo R \& Wilson JM 2002 Noninvasive gene transfer to the lung for systemic delivery of therapeutic proteins. Journal of Clinical Investigation 110 499-504.

Barzon L, Bonaguro R, Palu G \& Boscaro M 2000 New perspectives for gene therapy in endocrinology. European Journal of Endocrinology 143 447-466.

Baum BJ, Berkman ME, Marmary Y, Goldsmith CM, Baccaglini L, Wang S, Wellner RB, Hoque AT, Atkinson JC, Yamagishi H, Kagami H, Parlow AF \& Chao J 1999 Polarized secretion of transgene products from salivary glands in vivo. Human Gene Therapy $102789-2797$.

Baum BJ, Wellner RB \& Zheng C 2002 Gene transfer to salivary glands. International Review of Cytology 213 93-146.

Bazan JF 1989 A novel family of growth factor receptors: a common binding domain in the growth hormone, prolactin, erythropoietin and IL-6 receptors, and the p 75 IL-2 receptor beta-chain. Biochemical and Biophysical Research Communications 164 788-795.

Bohl D, Bosch A, Cardona A, Salvetti A \& Heard JM 2000 Improvement of erythropoiesis in beta-thalassemic mice by continuous erythropoietin delivery from muscle. Blood $\mathbf{9 5}$ 2793-2798

Carroll RJ, Hammer RE, Chan SJ, Swift HH, Rubenstein AH \& Steiner DF 1988 A mutant human proinsulin is secreted from islets of Langerhans in increased amounts via an unregulated pathway. PNAS 85 8943-8947.

Castle D \& Castle A 1998 Intracellular transport and secretion of salivary proteins. Critical Reviews in Oral Biology and Medicine 9 $4-22$.

Chan SJ, Seino S, Gruppuso PA, Schwartz R \& Steiner DF 1987 A mutation in the $\mathrm{B}$ chain coding region is associated with impaired proinsulin conversion in a family with hyperproinsulinemia. PNAS 84 2194-2197.

Chao H, Monahan PE, Liu Y, Samulski RJ \& Walsh CE 2001 Sustained and complete phenotype correction of hemophilia B mice following intramuscular injection of AAV1 serotype vectors. Molecular Therapy 4 217-222.

Chiorini JA, Wendtner CM., Urcelay E, Safer B, Hallek M \& Kotin RM 1995 High-efficiency transfer of the T cell co-stimulatory molecule B7-2 to lymphoid cells using high-titer recombinant adeno-associated virus vectors. Human Gene Therapy 6 1531-1541.

Cook DI, Van Lennep EW, Roberts ML \& Young JA 1994 Secretion by the major salivary glands. In Physiology of the gastrointestinal tract. 3rd edition, pp 1016-1117. Ed LR Johnson. New York: Raven Press.

Crystal RG 1995 The gene as a drug. Nature Medicine 1 15-17.

Dannies P 2002 Mechanisms for storage of prolactin and growth hormone in secretory granules. Molecular Genetics and Metabolism $\mathbf{7 6}$ 6-13.

Dube S, Fisher JW \& Powell JS 1988 Glycosylation at specific sites of erythropoietin is essential for biosynthesis, secretion, and biological function. Journal of Biological Chemistry 263 17516-17521.

Gerdes HH \& Glombik MM 1999 Signal-mediated sorting to the regulated pathway of protein secretion. Anatomischer Anzeiger 181 447-453.

Goldspink G 2003 Skeletal muscle as an artificial endocrine tissue. Best Practice and Research Clinical Endocrinology and Metabolism 17 211-222.

Harding TC, Koprivnikar KE, Tu GH, Zayek N, Lew S, Subramanian A, Sivakumaran A, Frey D, Ho K, VanRoey MJ, Nichols TC, Bellinger DA, Yendluri S, Waugh J, McArthur J, Veres G \& Donahue BA 2004 Intravenous administration of an AAV-2 vector for the expression of factor IX in mice and a dog model of hemophilia B. Gene Therapy 2004 204-213.

He X, Goldsmith CM, Marmary Y, Wellner RB, Parlow AF, Nieman LK \& Baum BJ 1998 Systemic action of human growth hormone following adenovirus-mediated gene transfer to rat submandibular glands. Gene Therapy 5 537-541.
Hoque AT, Baccaglini L \& Baum BJ 2001 Hydroxychloroquine enhances the endocrine secretion of adenovirus-directed growth hormone from rat submandibular gland in vivo. Human Gene Therapy 12 1333-1341.

Isenman L, Liebow C \& Rothman S 1999 The endocrine secretion of mammalian digestive enzymes by exocrine glands. American Journal of Physiology 276 E223-E232.

Johnston J, Tazelaar J, Rivera VM, Clackson T, Gao GP \& Wilson JM 2003 Regulated expression of erythropoietin from an AAV vector safely improves the anemia of beta-thalassemia in a mouse model. Molecular Therapy 7 493-497.

Kagami H, Atkinson JC, Michalek SM, Handelman B, Yu S, Baum BJ \& O'Connell BC 1998 Repetitive adenovirus administration to the parotid gland: role of immunological barriers and induction of oral tolerance. Human Gene Therapy 9 305-313.

Kaludov N, Handelman B \& Chiorini JA 2002 Scalable purification of adeno-associated virus type 2 , 4 , or 5 using ion-exchange chromatography. Human Gene Therapy 13 1235-1243.

Kay MA, Glorioso JC \& Naldini L 2001 Viral vectors for gene therapy: the art of turning infectious agents into vehicles of therapeutics. Nature Medicine 7 33-40.

Kelly RB 1985 Pathways of protein secretion in eukaryotes. Science $23025-32$

Kendall RG 2001 Erythropoietin. Clinical and Laboratory Haematology 23 71-80.

Kok MR, Yamano S, Lodde BM, Wang J, Couwenhoven RI, Yakar S, Voutetakis A, Leroith D, Schmidt M, Afione S, Pillemer SR, Tsutsui MT, Tak PP, Chiorini JA \& Baum BJ 2003 Local adeno-associated virus-mediated interleukin 10 gene transfer has disease-modifying effects in a murine model of Sjogren's syndrome. Human Gene Therapy 14 1605-1618.

Lai CM, Lai YK \& Rakoczy PE 2002 Adenovirus and adeno-associated virus vectors. DNA and Cell Biology 21 895-913.

Loh YP, Maldonado A, Zhang C, Tam WH \& Cawley N 2002 Mechanisms of sorting pro-opiomelanocortin and pro-enkephalin to the regulated secretory pathway of neuroendocrine cells. Annals of the New York Academy of Sciences 971 416-425.

Marmorstein AD, Csaky KG, Baffi J, Lam L, Rahaal F \& Rodriguez-Boulan 2000 Saturation of, and competition for entry into, the apical secretory pathway. PNAS 97 3248-3253.

Mittereder N, March KL \& Trapnell BC 1996 Evaluation of the concentration and bioactivity of adenovirus vectors for gene therapy. Journal of Virology 70 7498-7509.

Mujais SK, Beru N, Pullman TN \& Goldwasser E 1999 Erythropoietin is produced by tubular cells of the rat kidney. Cell Biochemistry and Biophysics 30 153-166.

Samakoglu S, Bohl D \& Heard JM 2002 Mechanisms leading to sustained reversion of beta-thalassemia in mice by doxycyclinecontrolled Epo delivery from muscles. Molecular Therapy 6 793-803.

Snyder RO, Miao CH, Patijn GA, Spratt SK, Danos O, Nagy D, Gown AM, Winther B, Meuse L, Cohen LK, Thompson AR \& Kay MA 1997 Persistent and therapeutic concentrations of human factor IX in mice after hepatic gene transfer of recombinant AAV vectors. Nature Genetics 16 270-276.

Voutetakis A, Wang J \& Baum BJ 2004a Utilizing endocrine secretory pathways in salivary glands for systemic gene therapeutics. Journal of Cellular Physiology 199 1-7.

Voutetakis A, Kok MR, Zheng C, Bossis I, Wang J, Cotrim AP, Marracino N, Goldsmith CM, Chiorini JA, Loh YP, Nieman LK \& Baum BJ $2004 b$ Re-engineered salivary glands are stable endogenous bioreactors for systemic gene therapeutics. PNAS 101 3053-3058.

Wang J, Voutetakis A, Zheng C \& Baum BJ 2004 Rapamycin control of exocrine protein levels in saliva after adenoviral vector-mediated gene transfer. Gene Therapy 11 729-733.

Wang J, Cawley NX, Voutetakis A, Rodriguez YM, Goldsmith CM, Nieman LK, Hoque S, Frank SJ, Snell CR, Loh YP \& Baum BJ 
2005 Partial re-direction of transgenic human growth hormone secretion from rat salivary glands. Human Gene Therapy (in press).

Yamano S, Huang LY, Ding C, Chiorini JA, Goldsmith CM, Wellner RB, Golding B, Kotin RM, Scott DE \& Baum BJ 2002

Recombinant adeno-associated virus serotype 2 vectors mediate stable interleukin 10 secretion from salivary glands into the bloodstream. Human Gene Therapy 13 287-298.

Zheng C, Hoque AT, Braddon VR, Baum BJ \& O'Connell BC 2001 Evaluation of salivary gland acinar and ductal cell-specific promoters in vivo with recombinant adenoviral vectors. Human Gene Therapy 12 2215-2223.

Zufferey R \& Aebischer P 2004 Salivary glands and gene therapy: the mouth waters. Gene Therapy 11 1425-1426.

Received 27 January 2005

Accepted 16 March 2005 